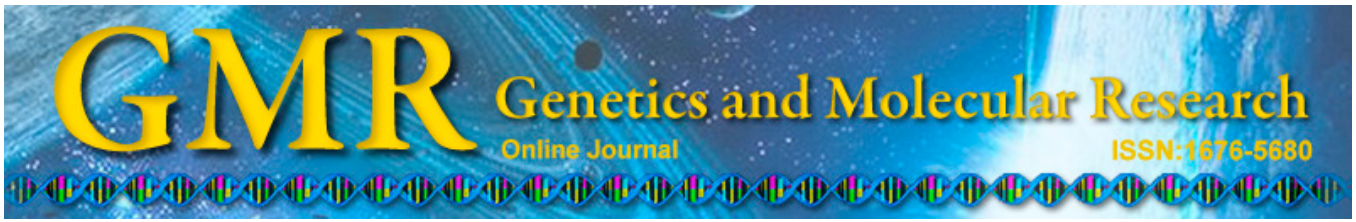

\title{
Allele frequencies of microsatellite loci for genetic characterization of a Sicilian bovine population
}

\author{
M. Cosenza, S. Reale, T. Lupo, F. Vitale and S. Caracappa \\ Experimental Zooprophylaxis Institute of Sicily, Palermo, Italy \\ Corresponding author: S. Reale \\ E-mail: stefano.reale@izssicilia.it
}

Genet. Mol. Res. 14 (1): 691-699 (2015)

Received November 14, 2013

Accepted March 24, 2014

Published January 30, 2015

DOI http://dx.doi.org/10.4238/2015.January.30.12

\begin{abstract}
Short tandem repeats are used as an effective method to trace DNA markers in genotyping. Using a standardized kit, we tested 11 microsatellite markers recommended by the International Society for Animal Genetics (ISAG) in a sample of 495 Sicilian cattle. The aim of this study was to investigate the allele frequencies in the Sicilian cattle population to provide a reference database and at the same time to assess the use of the ISAG microsatellite panel for pedigree analysis. DNA samples were collected from blood and amplified in an 11-plex polymerase chain reaction (PCR); PCR products were injected in a 3130 Genetic Analyzer. All loci showed high mean polymorphism information content (0.768), and the observed mean heterozygosity was less than the expected value (0.732 vs 0.794 , respectively). The exact test for Hardy-Weinberg proportions, allele number, and inbreeding coefficient were calculated. Our results indicated that equilibrium was not always maintained. The observed mean homozygote value exceeded the expected value (132.81 vs 102.14), but no evidence for allele dropout was found. These results could be explained by a nonrandom mating; further studies using a larger number of animals could confirm or invalidate this hypothesis. The probability of identity and
\end{abstract}


exclusion of a locus were also estimated and proved to be useful in paternity testing. The ISAG microsatellite panel is useful to screen the Sicilian bovine kinship. Currently, an allele frequency database is being constructed.

Key words: Microsatellite; Sicilian cattle; Frequency database; Allele frequencies

\section{INTRODUCTION}

In the last few years, the genetic structure of breeding animals has been described. Biodiversity conservation has been considered the main issue (Martín-Burriel et al., 2007) to prevent the loss of genetic variability. In September 2012, the cattle population in Sicily amounted to 347,268 animals (National Cattle Database of Teramo, Italy) with a strong dominance of females over males $(275,016$ vs 72,252). For this reason, breeding cattle was subjected to artificial selection (Bruford et al., 2003) that changed allele frequencies and created a serious loss of biodiversity. Today, the most representative cattle species in Sicily is a half-breed race ( $72 \%$ of the cattle population); Frisona and Limousine cattle comprise 7.1 and $4.5 \%$ of the population, respectively (National Cattle Database of Teramo, Italy). The use of short tandem repeats as DNA markers in genotyping represents an effective support for individual identification and parentage control in cattle (e.g., Ǩehout et al., 2006; Ozkan et al., 2009), horse breeds (Luis et al., 2002), sheep-goats (Lawson et al., 2007), and pigs (Putnová et al., 2003). In the last two decades, this approach has become the most reliable molecular marker for forensic analysis. Microsatellites are recognized as genetic markers because of their random distribution (Tautz and Renz, 1984), co-dominant mode of inheritance (Barbarà et al., 2007), discriminant power (e.g., Barendse et al., 1994), and overall ability for simultaneous analysis (Cañón et al., 2001). Microsatellite markers represent the gold standard for unequivocal determination of the genetic identity and/or parentage, even with limited sample quantities (Taberlet et al., 1996) or when DNA is degraded. They can also be used to trace the meat through the production chain (Vázquez et al., 2004), to study genetic diversity in cattle (Radko et al., 2005), and to select animals in breeding programs. Currently, more than 1000 microsatellite markers have been evaluated for cattle (e.g., Barendse et al., 1994; Kappes et al., 1997). Although many of these studies were conducted using European cattle (MacHugh et al., 1998), the Sicilian cattle population has not been studied. Kinship and/or identity analysis for traceability and consanguinity investigations use the allele frequencies of the local population (e.g., Radko et al., 2005; Cervini et al., 2006; Carolino et al., 2009) from a reference database. A reference database did not exist in Sicily until now, and microsatellite analysis has not been performed on Sicilian cattle. Additionally, allele frequency studies to evaluate microsatellite informativeness and their efficiency are lacking. In 2006, the International Society for Animal Genetics (ISAG) recommended a panel of nine microsatellite loci for cattle genetic analysis: TGLA227 (Georges and Massey, 1992), BM2113 (Sunden et al., 1993), ETH10 (Toldo et al., 1993), SPS115 (Baylor College of Medicine Human Genome Sequencing Center, 2006), TGLA126 (Georges and Massey, 1992), TGLA122 (Georges and Massey, 1992), INRA023 (Vaiman et al., 1994), ETH225 (Steffen et al., 1993), and BM1824 (Barendse et al., 1994). In 2008, the ISAG added three additional microsatellite loci: BM1818 (Bishop et al., 1994), ETH3 
(Toldo et al., 1993), and TGLA53 (Georges and Massey, 1992). The aim of this study was to test the 11 microsatellite markers that were suggested by the ISAG and to evaluate genetic variability to create a database of allele frequencies and improve parental definitions and genetic traceability of the Sicilian cattle population.

\section{MATERIAL AND METHODS}

\section{DNA extraction and multiplex-polymerase chain reaction (PCR)}

Blood samples of 495 registered related and unrelated cattle belonging to halfbreed species were collected. Cattle were sampled from several different breeding areas that were representative of the Sicilian population. Genomic DNA was extracted and purified from whole blood using a commercial kit (PureLink Genomic DNA Mini Kit, Invitrogen, Carlsbad, CA, USA) according to the manufacturer protocol. DNA samples were stored at $-20^{\circ} \mathrm{C}$. DNA fragments were amplified in 11-plex PCRs using a certified commercial kit (StockMarks for Cattle Bovine Genotyping Kit, Applied Biosystems, Foster City, CA, USA) according to manufacturer instructions. PCRs were carried out using a thermocycler (9700 Applied Biosystems, San Diego, CA, USA). Multiplex-PCR products were analyzed using an ABI PRISM 3130 Genetic Analyzer (Applied Biosystems, San Diego, CA, USA) using the GeneScan-500 ROX Size Standard (Applied Biosystems, Foster City, CA, USA). Genotypic profiles were read and analyzed using the GeneMapper ID v4.0 software (Applied Biosystems).

\section{Statistical analysis}

Statistical analysis of data generated from the 11 markers that were analyzed was performed using GenAlEx (Peakall and Smouse, 2012), PowerMarker (Liu and Muse, 2005), and Micro-Checker (Van Oosterhout et al., 2004) softwares, which are useful tools for the analysis of genetic populations because they use algorithms that allow the management of a variety of data. The number of effective alleles $\left(N_{\mathrm{E}}\right)$, allele number $\left(N_{\mathrm{A}}\right)$, allele frequency, observed and expected heterozygosities $\left(H_{\mathrm{O}}\right.$ and $H_{\mathrm{E}}$, respectively), probability of identity of a locus (PI), probability of exclusion of a locus (PE), and the deviation probability from the Hardy-Weinberg equilibrium (HWE) were obtained using the GenAlEx v6.5 software. The expected homozygosity $\left(\mathrm{Hom}_{\mathrm{E}}\right)$, observed homozygosity $\left(\mathrm{Hom}_{\mathrm{O}}\right)$, homozygosity excess, evidence for null allele, evidence for large allele dropout, and evidence for scoring error due to stuttering were obtained using the Micro-Checker v2.2 software. The polymorphism information content (PIC), inbreeding coefficient, genotype number $\left(N_{\mathrm{G}}\right)$, major allele frequency $\left(M_{\mathrm{AF}}\right)$, and major genotype frequency $\left(M_{\mathrm{GF}}\right)$ were investigated using the PowerMarker v3.25 software.

\section{RESULTS}

In total, 495 related and unrelated animals were genotyped. Information about the 11 microsatellites that were investigated is presented in Tables 1-5. Using the method that was described by Barker (1994), the 11 microsatellite loci tested in this study were used to evaluate the genetic diversity in Sicilian cattle breeds $\left(N_{\mathrm{A}}>4\right)$ (Table 1). All the evaluated microsatel- 
lite loci were polymorphic with an $N_{\mathrm{A}}$ of 136, an average of 12.36 alleles per locus, and a range of 5 (BM1824) to 23 (TGLA122) alleles per locus. The $N_{\mathrm{E}}$ value differs from the $N_{\mathrm{A}}$ value and ranged from 3.27 (TGLA126) to 8.85 (TGLA53) alleles per locus with an average of 5.39 alleles per locus. The $N_{\mathrm{E}} / N_{\mathrm{A}}$ ratio had a mean of 0.469 and ranged from 0.216 (TGLA122) to 0.817 (BM1824). The mean $M_{\mathrm{AF}}$ was 0.321 and ranged from 0.185 (TGLA227) to 0.494 (ETH3). Despite this, the polymorphism and informativeness of ETH10, ETH3, TGLA126, and SPS115 were lower than those of other loci because their $M_{\mathrm{AF}}$ values were close to 0.5 . The PIC is a parameter that indicates the degree of marker informativeness. According to the parameters established by Botstein et al. (1980), all microsatellite loci in this study were highly informative (PIC > 0.5), with a mean PIC of 0.768 for all loci. The PIC varied from 0.877 (TGLA53) to 0.654 (TGLA126). The mean $H_{\mathrm{O}}$ and $H_{\mathrm{E}}$ were 0.732 and 0.794 , respectively. TGLA53 showed the highest level of heterozygosity $(0.887)$, whereas the SPS115 marker showed the lowest level of heterozygosity (0.628). The probability of finding another animal with the same genetic profile using these 11 markers (PI for increasing locus combinations) was $5.3 \times 10^{-14}$ and is shown in Table 1 for each locus. The PE by locus for two putative parents had an average of 0.794, ranged from 0.92 (TGLA53) to 0.66 (TGLA126), and followed the pattern that was observed for PIC values. In the Sicilian cattle population, the combined PE exceeded $99 \%$ for the ISAG microsatellite panel when the genotypes of both parents are known, when the genotype of only one parent is known, and when the two putative parents are excluded (data not shown).

Table 1. Genetic characteristics of the microsatellite markers that were tested in the Sicilian cattle population
$(\mathrm{N}=495)$.
\begin{tabular}{llccccccccc} 
\\
\hline Locus & Observed size range (bp) & $N_{\mathrm{A}}$ & $N_{\mathrm{E}}$ & $N_{\mathrm{E}} / N_{\mathrm{A}}$ & $M_{\mathrm{AF}}$ & $H_{\mathrm{O}}$ & $H_{\mathrm{E}}$ & PIC & PE & PI \\
\hline TGLA227 & $74-102$ & 15 & 7.878 & 0.525 & 0.185 & 0.772 & 0.873 & 0.86 & 0.9 & 0.029 \\
BM2113 & $120-146$ & 12 & 6.877 & 0.573 & 0.202 & 0.747 & 0.855 & 0.837 & 0.87 & 0.038 \\
TGLA53 & $153-189$ & 17 & 8.855 & 0.521 & 0.217 & 0.887 & 0.887 & 0.877 & 0.92 & 0.023 \\
ETH10 & $208-224$ & 9 & 3.933 & 0.437 & 0.398 & 0.695 & 0.746 & 0.709 & 0.72 & 0.1 \\
SPS115 & $242-254$ & 10 & 4.251 & 0.425 & 0.419 & 0.628 & 0.765 & 0.741 & 0.78 & 0.079 \\
TGLA126 & $114-124$ & 8 & 3.27 & 0.408 & 0.475 & 0.663 & 0.694 & 0.654 & 0.66 & 0.13 \\
TGLA122 & $138-162$ & 23 & 4.988 & 0.216 & 0.307 & 0.725 & 0.8 & 0.775 & 0.81 & 0.065 \\
INRA023 & $198-220$ & 15 & 6.597 & 0.439 & 0.228 & 0.786 & 0.848 & 0.83 & 0.87 & 0.041 \\
ETH3 & $106-130$ & 12 & 3.286 & 0.273 & 0.494 & 0.679 & 0.696 & 0.664 & 0.69 & 0.12 \\
ETH225 & $134-146$ & 10 & 5.312 & 0.531 & 0.318 & 0.723 & 0.812 & 0.788 & 0.82 & 0.059 \\
BM1824 & $176-190$ & 5 & 4.086 & 0.817 & 0.288 & 0.743 & 0.755 & 0.711 & 0.7 & 0.1 \\
Mean & & 12.36 & 5.39 & 0.469 & 0.321 & 0.732 & 0.794 & 0.768 & 0.794 & 0.071 \\
\hline
\end{tabular}

$N_{\mathrm{A}}=$ number of alleles; $N_{\mathrm{E}}=$ number of effective alleles; $M_{\mathrm{AF}}=$ major allele frequency; $H_{\mathrm{O}}=$ observed heterozygosity; $H_{\mathrm{E}}=$ expected heterozygosity; PIC = polymorphic information content; $\mathrm{PE}=$ probability of exclusion; PI = probability of identity.

The frequencies of each allele at each microsatellite marker are shown in Table 2.

The $\mathrm{Hom}_{\mathrm{E}}$ and $\mathrm{Hom}_{\mathrm{O}}$ averaged 102.14 and 132.81, respectively (Table 3). All loci significantly deviated from HWE $(\mathrm{P}<0.01)$ except ETH10 and TGLA126 (Table 4). The $N_{\mathrm{G}}$ value, the most representative genotypes for each locus and their $M_{\mathrm{GF}}$ are shown in Table 5. TGLA53 showed the highest number of genotypes $(\mathrm{N}=89)$. The lowest $N_{\mathrm{G}}$ was 15 in BM1824, and the average was 47.18. Inbreeding coefficients were calculated on the basis of $H_{\mathrm{E}}$ versus $H_{\mathrm{O}}$. The mean inbreeding coefficient was 0.081 . SPS115 showed the highest value (0.179), whereas TGLA53 showed the lowest value (0.001). 


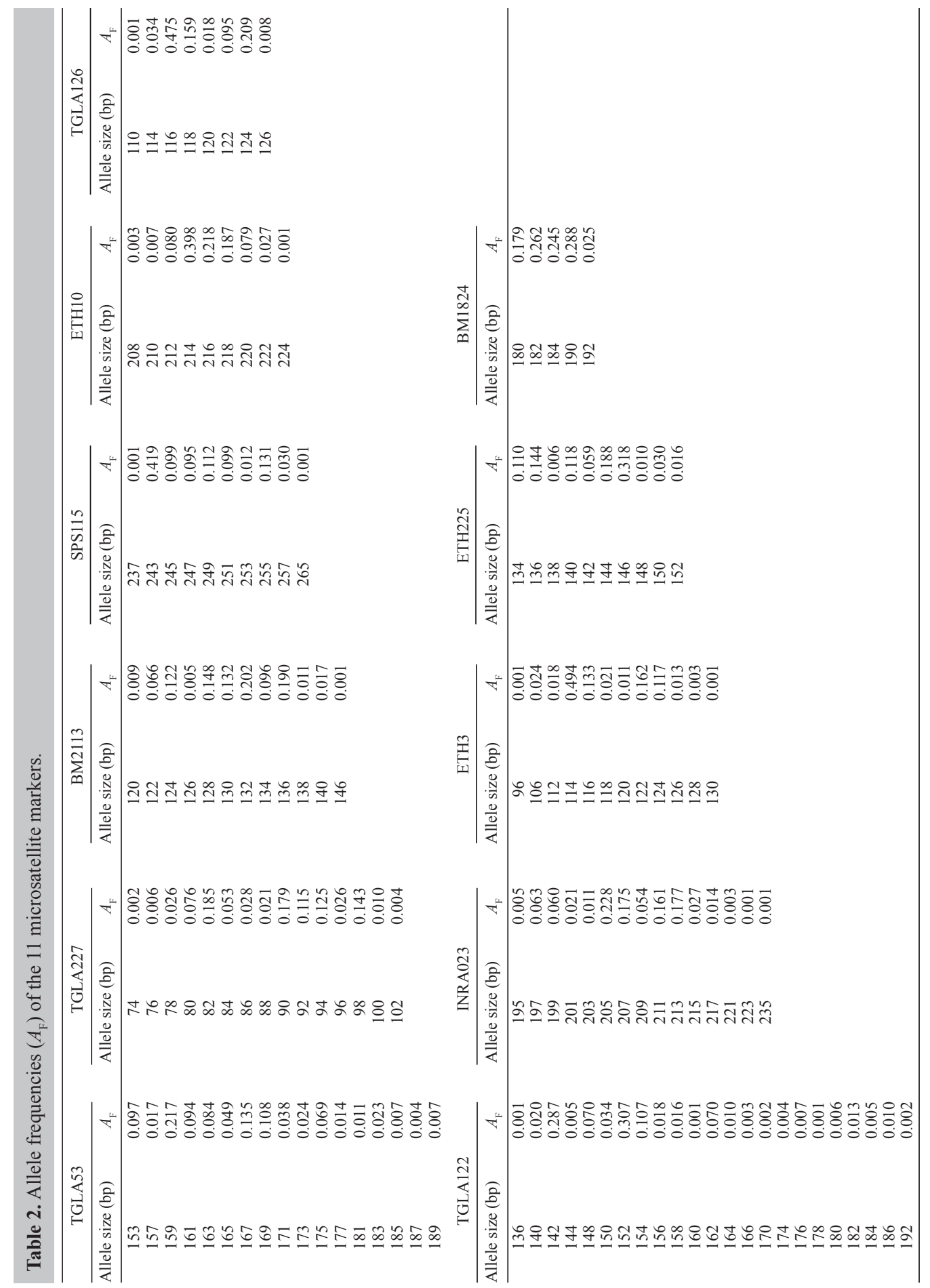




\begin{tabular}{|c|c|c|c|c|c|c|}
\hline Locus & $\operatorname{Hom}_{\mathrm{E}}$ & $\mathrm{Hom}_{\mathrm{O}}$ & Hom $_{\mathrm{EXC}}$ & Null-Al & Dropout & Stutter \\
\hline TGLA227 & 62.83 & 113 & $*$ & $*$ & - & - \\
\hline BM2113 & 71.98 & 125 & $*$ & $*$ & - & - \\
\hline TGLA53 & 55.89 & 56 & - & - & - & - \\
\hline ETH10 & 125.87 & 151 & $*$ & $*$ & - & - \\
\hline SPS115 & 116.43 & 184 & $*$ & $*$ & - & - \\
\hline TGLA126 & 151.37 & 167 & - & - & - & - \\
\hline TGLA122 & 99.24 & 136 & * & * & - & - \\
\hline INRA023 & 75.03 & 106 & * & * & - & - \\
\hline ETH3 & 150.61 & 159 & - & - & - & - \\
\hline ETH225 & 93.18 & 137 & $*$ & $*$ & - & $*$ \\
\hline BM1824 & 121.15 & 127 & - & - & - & - \\
\hline Mean & 102.14 & 132.81 & & & & \\
\hline
\end{tabular}

Hom $_{\mathrm{E}}=$ expected homozygosity; Hom ${ }_{\mathrm{O}}=$ observed homozygosity; Hom ${ }_{\mathrm{EXC}}=$ excess homozygosity; Null-Al = evidence for null allele; Dropout = evidence for large allele dropout; Stutter = evidence for scoring error due to stuttering; (*) presence; (-) absent.

Table 4. Hardy-Weinberg equilibrium of the Sicilian cattle population based on the 11 microsatellite markers.

\begin{tabular}{lcc}
\hline Locus & Probability & P value \\
\hline TGLA227 & 0.000 & $* * *$ \\
BM2113 & 0.000 & $* * *$ \\
TGLA53 & 0.001 & $* * *$ \\
ETH10 & 0.128 & ns \\
SPS115 & 0.000 & $* * *$ \\
TGLA126 & 0.177 & ns \\
TGLA122 & 0.000 & $* * *$ \\
INRA023 & 0.000 & $* * *$ \\
ETH3 & 0.000 & $* * *$ \\
ETH225 & 0.000 & $* * *$ \\
BM1824 & 0.005 & $* *$ \\
\hline
\end{tabular}

ns $=$ not significant. $* * \mathrm{P}<0.01 ; * * * \mathrm{P}<0.001$.

Table 5. Genotypic information about the 11 investigated short tandem repeat loci.

\begin{tabular}{|c|c|c|c|c|c|c|}
\hline Locus & $N_{\mathrm{G}}$ & Allele 1 & Allele 2 & Count & $M_{\mathrm{GF}}$ & $\mathrm{F}$ \\
\hline TGLA227 & 70 & 10 & 6 & 28 & 0.056 & 0.117 \\
\hline BM2113 & 51 & 11 & 9 & 36 & 0.072 & 0.126 \\
\hline TGLA53 & 89 & 12 & 7 & 28 & 0.056 & 0.001 \\
\hline ETH10 & 25 & 9 & 9 & 88 & 0.177 & 0.069 \\
\hline SPS115 & 35 & 5 & 5 & 123 & 0.248 & 0.179 \\
\hline TGLA126 & 25 & 7 & 7 & 120 & 0.242 & 0.046 \\
\hline TGLA122 & 74 & 10 & 5 & 73 & 0.147 & 0.093 \\
\hline INRA023 & 59 & 10 & 7 & 41 & 0.082 & 0.074 \\
\hline ETH3 & 34 & 13 & 13 & 122 & 0.246 & 0.025 \\
\hline ETH225 & 42 & 7 & 8 & 75 & 0.151 & 0.11 \\
\hline BM1824 & 15 & 11 & 7 & 85 & 0.171 & 0.016 \\
\hline Mean & 47.18 & & & & 0.149 & 0.081 \\
\hline
\end{tabular}

$N_{\mathrm{G}}=$ number of genotypes; Count $=$ number of times in which genotype Allele 1/Allele 2 appears in the population; $M_{\mathrm{GF}}=$ major genotype frequency (refers to Allele 1/Allele 2); F = inbreeding coefficient.

\section{DISCUSSION}

This is the first study that used a standardized kit to evaluate microsatellite DNA markers to determine the genetic variability of the Sicilian cattle population. This study aimed 
to create an allele frequency database and to assess the use of the ISAG microsatellite panel to verify the parentage. This study proved the ability of the ISAG microsatellite panel to test the parental definition and genetic traceability of the Sicilian cattle population. In our study, the population showed a significant deficiency in the $H_{\mathrm{O}}$ value compared to the $H_{\mathrm{E}}$ value according to the HWE. This fact can often indicate positive assortative mating with deviations from panmixia. Decreased panmictic indices increase the number of homozygous individuals in the population. Loss of heterozygosity also can include the Wahlund effect because populations are fragmented into subpopulations, allele dropout, and null alleles caused by mutations in primer binding site (Pemberton et al., 1995). In the last case, an undetected allele may cause parents to be incorrectly assigned (Holm et al., 2001) and incorrect genotypes. Because of this, we also recognize the heterozygote deficiency of some loci (ETH10, SPS115, TGLA126, and ETH3), in which genotypes showed predominant allele 1/allele 2 homozygosis. This finding was related to the lower informativeness of the same loci because their $M_{\mathrm{AF}}$ values were close to 0.5 . Finally, we observed a homozygote excess compared to the expected value. The $N_{\mathrm{E}}$, which is a function of the expected heterozygosis, showed a strong uneven distribution compared to respective $N_{\mathrm{A}}$ values. According to the study by Carolino et al. (2009), the $N_{\mathrm{E}} /$ $N_{\mathrm{A}}$ ratio describes the allelic distribution depending on the number of alleles at a given locus. Therefore, a high ratio indicates a prevalence of many alleles at a given locus. A low $N_{\mathrm{E}} / N_{\mathrm{A}}$ ratio shows the prevalence of only a limited number of alleles despite a high number of alleles, for example, marker TGLA122. Only BM1824 revealed a nonlinear relationship with the $H_{\mathrm{E}}$. Thanks to this result, we concluded that allele sets have very different frequencies. We found statistically significant deviations from HWE for all loci except ETH10 and TGLA126. This could be explained by several consequences of the Wahlund effect, such as a loss of heterozygosity and inbreeding. The inbreeding coefficient value is probably explained by the genetic isolation of breeding farms; therefore, breeding cattle has been subjected to nonrandom mating, which is also because the result of the strong disproportion between males and females.

The cumulative PI demonstrated the high discrimination power of these 11 markers in paternity testing of the Sicilian cattle population, with PE $>99.99 \%$ (1 - PI). Many authors (e.g., Heyen et al., 1997; Luikart et al., 1999) described paternity incompatibility if putative parents and offspring differed at least in two loci to avoid misidentification due to allelic dropout or null alleles. In this report, we rejected a direct relationship if the genotypic profiles of parents and offspring differed at a single locus if they were heterozygotes at the given locus. However, when genotypes differed only in one homozygous locus, we required one more mismatched locus to discard paternity. The disproportion between male and female animals (1:4) leads to an increased level of inbreeding in Sicily and to the spread of very similar genotypes in the population. To validate our results, seven loci that were analyzed using MicroCheker showed evidence for null alleles, which was suggested by the excess homozygotes for most alleles. Only ETH225 showed evidence for scoring error due to stuttering, and none of these loci had large allele dropout. It is not clear whether the homozygote excess is due to null alleles or if it really reflects the genotypes of the Sicilian cattle population genotypes.

Our purpose was to develop the first Sicilian cattle allele frequency database for genetic traceability. The ISAG panel showed that some alleles are widely distributed while others are present discontinuously within the population. The 11 ISAG microsatellite markers are reliable in parentage verification and identity tests of Sicilian cattle population. Nevertheless, their reliability depends on the consanguinity of the breeding. Additional information supplied by extra-microsatellite markers could provide more useful information to better define the 
relationships. Until now, little information was available about Sicilian cattle population microsatellites, and more investigations using a large number of animals are necessary to widen the allele frequency database.

\section{Conflicts of interest}

The authors declare no conflict of interest.

\section{REFERENCES}

Barbarà A, Palma-Silva C, Paggi GM, Bered F, et al. (2007). Cross-species transfer of nuclear microsatellite markers: potential and limitations. Mol. Ecol. 16: 3759-3767.

Barendse W, Armitage SM, Kossarek LM, Shalom A, et al. (1994). A genetic linkage map of the bovine genome. Nat. Genet. 6: 227-235.

Barker JSF (1994). A Global Protocol for Determining Genetic Distances Among Domestic Livestock Breeds. Proceedings of the 5th World Congress on Genetics Applied to Livestock Production, Guelph and Ontario, 21: 501-508.

Baylor College of Medicine Human Genome Sequencing Center (2006). Bovine Whole Genome Assembly Release Btau_3.1. Available at [https://www.hgsc.bcm.edu/content/bovine-genome-project].

Bishop MD, Kappes SM, Keele JW, Stone RT, et al. (1994). A genetic linkage map for cattle. Genetics 136: 619-639.

Botstein D, White RL, Skolnick M and Davis RW (1980). Construction of a genetic linkage map in man using restriction fragment length polymorphisms. Am. J. Hum. Genet. 32: 314-331.

Bruford MW, Bradley DG and Luikart G (2003). DNA markers reveal the complexity of livestock domestication. Nat. Rev. Genet. 4: 900-910.

Cañón J, Alexandrino P, Bessa I, Carleos C, et al. (2001). Genetic diversity measures of local European beef cattle breeds for conservation purposes. Genet. Sel. Evol. 33: 311-332.

Carolino I, Sousa CO, Ferreira S, Carolino N, et al. (2009). Implementation of a parentage control system in Portuguese beef-cattle with a panel of microsatellite markers. Genet. Mol. Biol. 32: 306-311.

Cervini M, Henrique-Silva F, Mortari N and Matheucci E Jr (2006). Genetic variability of 10 microsatellite markers in the characterization of Brazilian Nellore cattle (Bos indicus). Genet. Mol. Biol. 29: 486-490.

Georges M and Massey JM (1992). Polymorphic DNA Markers in Bovidae. World Intellectual Property Organization, Geneva (Patent application WO PUBL No. 92/13102).

Heyen DW, Beever JE, Da Y, Evert RE, et al. (1997). Exclusion probabilities of 22 bovine microsatellite markers in fluorescent multiplexes for semi-automated parentage testing. Anim. Genet. 28: 21-27.

Holm LE, Loeschcke V and Bendixen C (2001). Elucidation of the molecular basis of a null allele in a rainbow trout microsatellite. Mar. Biotechnol. 3: 555-560.

Kappes SM, Keele JW, Stone RT, McGraw RA, et al. (1997). A second-generation linkage map of the bovine genome. Genome Res. 7: 235-249.

Lawson HLJ, Byrne K, Santucci F, Townsend S, et al. (2007). Genetic structure of European sheep breeds. Heredity 99: 620-631.

Liu K and Muse SV (2005). PowerMarker: an integrated analysis environment for genetic marker analysis. Bioinformatics 21: 2128-2129.

Luikart G, Biju-Duval MP, Ertugrul O, Zagdsuren Y, et al. (1999). Power of 22 microsatellite markers in fluorescent multiplexes for parentage testing in goats (Capra hircus). Anim. Genet. 30: 431-438.

Luis C, Cothran GE and Oom MM (2002). Microsatellites in Portuguese autochthonous horse breeds: usefulness for parentage testing. Genet. Mol. Biol. 25: 131-134.

MacHugh DE, Loftus RT, Cunningham P and Bradley DG (1998). Genetic structure of seven European cattle breeds assessed using 20 microsatellite markers. Anim. Genet. 29: 333-340.

Martín-Burriel I, Rodellar C, Lenstra JA, Sanz A, et al. (2007). Genetic diversity and relationships of endangered Spanish cattle breeds. J. Hered. 98: 687-691.

Ozkan E, Soysal MI, Ozder M, Koban E, et al. (2009). Evaluation of parentage testing in the Turkish Holstein population based on 12 microsatellite loci. Livest. Sci. 124: 101-106.

Peakall R and Smouse PE (2012). GenAlEx 6.5: Genetic analysis in Excel. Population genetic software for teaching and research - an update. Bioinformatics 28: 2537-2539. 
Pemberton JM, Slate J, Bancroft DR and Barrett JA (1995). Nonamplifying alleles at microsatellite loci: a caution for parentage and population studies. Mol. Ecol. 4: 249-252.

Putnová L, Knoll A, Dvořák V and Dvořák J (2003). A novel porcine microsatellite panel for the identification of individuals and parentage control in the Czech Republic. Czech J. Anim. Sci. 48: 307-314.

Radko A, Zyga A, Zabek T and Slota E (2005). Genetic variability among Polish Red, Hereford and Holstein-Friesian cattle raised in Poland based on analysis of microsatellite DNA sequences. J. Appl. Genet. 46: 89-91.

Řehout V, Hradecká E and Čítek J (2006). Evaluation of parentage testing in the Czech population of Holstein cattle. Czech J. Anim. Sci. 51: 503-509.

Steffen P, Eggen A, Dietz AB, Womack JE, et al. (1993). Isolation and mapping of polymorphic microsatellites in cattle. Anim. Genet. 24: 121-124.

Sunden SLF, Stone RT, Bishop MD, Kappes SM, et al. (1993). A highly polymorphic bovine microsatellite locus: BM2113. Anim. Genet. 24: 69.

Taberlet P, Griffin S, Goossens B, Questiau S, et al. (1996). Reliable genotyping of samples with very low DNA quantities using PCR. Nucleic Acids Res. 24: 3189-3194.

Tautz D and Renz M (1984). Simple sequences are ubiquitous repetitive components of eukaryotic genomes. Nucleic Acids Res. 12: 4127-4138.

Toldo SS, Fries R, Steffen P, Neibergs HL, et al. (1993). Physically mapped, cosmid-derived microsatellite markers as anchor loci on bovine chromosomes. Mamm. Genome 4: 720-727.

Vaiman D, Mercier D, Moazami-Goudarzi K, Eggen A, et al. (1994). A set of 99 cattle microsatellites: characterization, synteny mapping, and polymorphism. Mamm. Genome 5: 288-297.

Van Oosterhout C, Hutchinson WF, Wills DPM and Shipley P (2004). MICRO-CHECKER: software for identifying and correcting genotyping errors in microsatellite data. Mol. Ecol. Notes 4: 535-538.

Vázquez JF, Pérez T, Ureña F, Gudín E, et al. (2004). Practical application of DNA fingerprinting to trace beef. J. Food Prot. 67: 972-979. 